\title{
Editorial $^{*}$
}

\section{T N C Vidya, Associate Editor}

Historical contingency is a large part of life itself. Although often dismissed in inspirational quotes, chance factors can affect evolutionary, historical, societal, and individual outcomes. One often wonders how the course of world history would have changed if Hitler had been able to pursue fine arts in Vienna as he had wanted to. The course of science is also subject to innumerable contingencies-from political regimes and social mores to serendipitous discoveries and fortuities in the lives of individual scientists. For instance, would relativity have been conceptualised if Einstein had not been able to avoid service in the military? Would the history of antibiotic use have changed significantly if Ernst Chain and Howard Florey had not decided to reexamine penicillin after the initial work by Fleming pointed to difficulties in its use? Is the next potential Ramanujan the little girl playing on a construction site or in a remote hamlet with no opportunity for schooling?

One of the what-ifs in the history of biology pertains to Nikolai Vavilov, the featured scientist of this issue. Nikolai Vavilov was a brilliant Russian plant geneticist. Affected by what he saw of his times and determined to end famine and hunger, Vavilov toiled tirelessly to improve crop varieties. He recognised the potential problem of genetic erosion in crop plants and travelled widely to collect and preserve natural varieties of crop plants and their wild relatives. He set up multiple seed banks, which went on to have hundreds of thousands of accessions. He also postulated hypotheses about patterns of variability of traits in related plant species and the centres of origin of cultivated plants. However, after Stalin took over the Soviet Union and the pseudoscientist Lysenko (who rejected Mendelian genetics) became

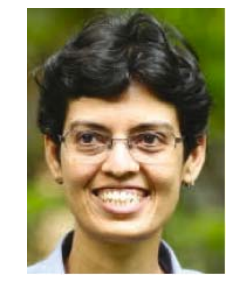

Email: tncvidya@jncasr.ac.in

*DOI: https://doi.org/10.1007/s12045-019-0901-6 
Stalin's favoured scientist, Vavilov (along with many other geneticists) was arrested and imprisoned. Vavilov ironically and tragically died of starvation in a Russian gulag. We are left to wonder what might have been if sociopolitical conditions had not cut short his life. The misadventures of Lysenko destroyed and held back genetics and other areas of biology in Russia for a long time. More recently, in 2010, the Pavlovsk Experimental Station, a field genebank set up by Vavilov, was in the news. Having survived the siege of Leningrad in 1941-1944, with scientists in charge of the station valiantly preferring to die of starvation rather than eat the edible collection in the genebank, the Pavlovsk Experimental Station came under threat of losing land to government-backed real estate development. However, vociferous international campaigning was able to stop it. The future of the station might depend on various contingencies. Sujata Deshpande has very nicely described Vavilov's life and work in Science versus Ideology: The Contribution and Martyrdom of Nikolai Vavilov in this issue. She has also selected an interesting Classics by Vavilov on 'The Law of Homologous Series in Variation', which was originally published in the Journal of Genetics.

The Nobel Prizes are announced in October each year, and the Prizes given in December. I am not personally a fan of at least the science prizes as they seem to stilt the way science is perceived. However, while being in the right place at the right time may greatly facilitate one's work, Nobel Laureates have often worked extremely hard and survived great adversities to achieve what they did. We have three articles in this issue describing the work behind the Nobel Prizes in Physiology or Medicine, Chemistry, and Physics. The 2019 Nobel Prize in Physiology or Medicine was awarded to William G Kaelin Jr, Sir Peter J Ratcliffe, and Gregg L Semenza for "their discoveries of how cells sense and adapt to oxygen availability." Mamatha Reddy explains the molecular mechanisms underlying oxygen sensing by cells. The 2019 Nobel Prize in Chemistry was awarded to John B Goodenough, M Stanley Whittingham, and Akira Yoshino for "the development of lithium-ion batteries". A Ramanan describes the 
history of batteries and the development and future of lithium-ion batteries. The 2019 Nobel Prize in Physics was awarded to James Peebles, Michel Mayor, and Didier Queloz "for contributions to our understanding of the evolution of the universe and Earth's place in the cosmos", and D J Saikia writes about this work.

Mahak Sharma has written in this issue, a wonderful book review of The Gene Machine, authored by the Nobel Laureate, Venkatraman Ramakrishnan. Venkatraman Ramakrishnan himself has discussed the role of chance in the way one's career proceeds, writing in his book "So I don't subscribe to the heroic narrative of science. Rather, some of us are fortunate enough to be the agents of important discoveries that would have been made anyway,..."

We continue two series in this issue How to Design Experiments in Animal Behaviour and Megaprojects, describing simple experiments that can be done with little money, and expensive, internationally collaborative projects, respectively. They each give different kinds of insights. In the ninth article of the first series, Raghavendra Gadagkar asks Why do Wasps Fight, and sets up elegant experiments to find out why. The second series, coordinated by K Indulekha, features the Facility for Antiproton and Ion Research (FAIR). Subhasis Chattopadhyay, R K Bhandari and Paolo Giubellino explain various aspects of this highly sophisticated facility, which is expected to serve a few thousand researchers in various subdisciplines of physics.

We also have two Classroom articles, on the validity of an experimental determination of Fermi energy, and on a very interesting problem of burning ropes to measure time.

Finally, and excitingly, Resonance will soon enter into its 25th year of publication. As part of the Silver Jubilee celebration, the Indian Academy of Sciences, in collaboration with St. Joseph's College (Autonomous), Bengaluru, will organise Resonance@ 25 - Science Workshop on 3rd and 4th January 2020. Please see the announcement in this issue. All are welcome to attend. 